\title{
A construção discursiva do futuro do trabalho: análise crítica de white papers e relatórios prospectivos ${ }^{1}$
}

\author{
Vander Casaqui' \\ https://orcid.org/0000-0001-7823-9861 \\ I - Universidade Metodista de São Paulo \\ São Paulo (SP), Brasil
}

Resumo: Este artigo aborda o futuro do trabalho como fenômeno comunicacional, por meio de sua análise como construção discursiva. Elegemos como objeto dois relatórios, dois documentos prospectivos: um assinado pelo World Economic Forum — talvez o maior porta-voz do capitalismo global - e outro da corporação Dell Technologies, expoente da economia digital mundial. Buscamos identificar de que forma esses discursos sobre o futuro do trabalho mobilizam códigos hegemônicos do neoliberalismo, compreendido como lógica social. Essa lógica pressupõe a produção de sujeitos, por meio de competências, perfis, como capital humano a ser gerido com eficácia. A metodologia é baseada na noção de discurso social de Angenot - que propõe a análise do espírito do tempo em sua disseminação nos discursos de dado contexto histórico e social.

Palavras-chave: Trabalho; cultura empreendedora; comunicação; discurso social; futuro.

\footnotetext{
Abstract: The discursive construction of the future of work: critical analysis of white papers and prospective reports - This article discusses the future of work as a communicational phenomenon, through its analysis

1 Versão revista e ampliada de artigo apresentado no XXXII Congreso Internacional ALAS PERÚ 2019, realizado de 1 a 6 de dezembro de 2019, na cidade de Lima, Perú. O presente trabalho foi realizado com apoio do CNPq, Conselho Nacional de Desenvolvimento Científico e Tecnológico Brasil (processo no. 303434/2019-8); e da Fundação de Amparo à Pesquisa do Estado de São Paulo (FAPESP), processo no. 2019/14365-7.
} 
as a discursive construction. We selected two reports, two forward-looking documents as object: one signed by the World Economic Forum - perhaps the greatest representative voice of global capitalism - and another by Dell Technologies, an exponent of the world digital economy. We seek to identify how these discourses about the future of work mobilize hegemonic codes of neoliberalism, understood as social logic. This logic presupposes the production of subjects, through skills, profiles, as human capital to be managed effectively. The methodology is based on Angenot's notion of social discourse - which proposes an analysis of the spirit of time in its dissemination in discourses of a given historical and social context.

Keywords: Work; entrepreneurial culture; Communication; social discourse; future.

\section{Introdução}

Qual é o futuro do trabalho? Acompanhamos, no contexto atual, a profusão e disseminação, via redes digitais, um sem número de instituições e agentes que procuram responder a essa questão. Esse exercício de futurologia está necessariamente pautado por uma visão de mundo e uma ideologia. Nesse sentido, nosso estudo está baseado na análise crítica dos discursos sobre o futuro do trabalho - tidos como construção de cenários a serviço de interesses corporativos e relacionados com os ideais e pressupostos da sociedade neoliberal (DARDOT; LAVAL, 2016). Essa produção discursiva, por sua vez, tem relação intrínseca com o espírito do tempo, analisado por meio da noção de discurso social de Angenot (2010). Os agentes que assumem esses discursos dissimulam seus interesses próprios, em nome de um suposto interesse público. Há, enfim, uma lógica biopolítica, uma antropotécnica, no sentido foucaultiano, que rege o exercício de pensar o futuro do trabalho, através de relatórios de institucionalidades, de documentos prospectivos sobre o tema.

O futuro é uma construção. Como aponta Morace (2013, p. 25): “O futuro representa uma imagem lançada adiante, como indica a palavra 'projeto', do latim projectus". Esse exercício de projetar significa lançar a imaginação em um tempo futuro. Morace alerta: o pensamento sobre o futuro não pode capturar o que virá, mas se restringe à consideração dos futuros possíveis. Como construção que especula, mas não diz respeito a um futuro já-dado, esse exercício tem um caráter ideológico - ainda mais quando se propõe a defender a ideia de um futuro de direção única, tido como verdade, como um retrato da realidade. 
A discussão sobre o futuro, que é bastante ampla, em nossa pesquisa é restrita ao mundo do trabalho, um tema tão atual como polêmico. Afinal, em um mundo capitalista de transformações radicais nas tecnologias e formas de trabalho e nos vínculos empregatícios, e, por derivação, das subjetividades produzidas a partir da atividade laboral, como projetar o seu futuro? Entre visões utópicas e distópicas, a própria noção de trabalho serviria a uma longa discussão, como indica Schwartz (2011): suas definições são múltiplas, e também marcadas ideologicamente. Marx discutia a atividade do trabalho como constituinte do ser social; o homem que produz, produz a si mesmo. A perspectiva ampla do trabalho, no contexto capitalista, tende a ser reduzida à dimensão do emprego, à transformação da força de trabalho em mercadoria.

Atualmente, a noção de trabalho é atravessada pelas lógicas do capitalismo flexível (SENNETT, 2007), confundindo-se com uma leitura expandida do que é a atividade empreendedora: os processos de precarização, de uberização, de desmonte das leis e vínculos trabalhistas por vezes são lidos, em chave positiva, como oportunidade para empreender, para ser "patrão de si próprio", para viver o ideal empresarial de si. Em síntese: vivemos um momento de transformações profundas da atividade laboral no presente, cujos sintomas são percebidos nas modulações da linguagem do capital, na emergência de uma rede de significados para justificar e positivar os impactos das mudanças do sistema na vida cotidiana dos trabalhadores.

Essas dimensões do trabalho contemporâneo, entre tantas, já permitem evidenciar que a noção de "futuro do trabalho" também não é algo simples, pois, na própria concepção das palavras, há visões distintas em jogo, inclusive embates discursivos implícitos. Neste artigo, essa noção será extraída da análise dos discursos e dos documentos que constroem cenários futuros sobre a atividade laboral. Para esse estudo elegemos dois documentos: o relatório The Future of Jobs Report, do World Economic Forum - WEF, em sua edição de 2018; e o documento Future of Work: Forecasting Emerging Technologies' Impact on Work in the Next Era of Human-Machine Partnerships, assinado pela empresa Dell Technologies, de 2019. A relevância desses relatórios para estudo parte, principalmente, do papel estratégico que as duas instituições assumem na configuração do capitalismo contemporâneo e no desenho de seu futuro: se o Fórum de Davos, o encontro anual promovido pelo WEF, é o local onde os grandes líderes mundiais discutem os rumos do sistema para os próximos anos; a Dell é um dos mais destacados players da economia mundial baseada na tecnologia digital, apontada de forma 
recorrente como decisiva para a construção do futuro da humanidade. Os relatórios assinados por essas duas organizações materializam sua visão de mundo em cenários que, por meio de recursos retóricos, elementos extraídos de pesquisas, estatísticas, adquirem o caráter de discurso competente sobre uma realidade que está por vir — dissimulando, assim, os interesses em jogo nessas construções discursivas.

\section{Acerca do método e dos pressupostos da abordagem analítica}

Como apontamos no início do artigo, adotamos uma postura crítica em relação ao objeto de estudo, que está relacionada ao conceito de contemporâneo por Agamben: segundo o autor, devemos exercer um olhar dissociado e anacrônico para o nosso tempo. Em suas próprias palavras: “contemporâneo é aquele que mantém fixo o olhar no seu tempo, para nele perceber não as luzes, mas o escuro. Todos os tempos são, para quem deles experimenta contemporaneidade, obscuros" (AGAMBEN, 2008, p. 62-63). A análise crítica dos discursos de documentos sobre o futuro do trabalho, que propomos por meio dessa pesquisa, está baseada na abordagem de Agamben, que nos sugere a necessidade de desnaturalização e tensionamento dos discursos que constituem certo cenário social, e não a sua aceitação como uma realidade já-dada - mesmo que seja em uma projeção de futuro, como discutimos adiante.

Na direção apontada por Agamben, destacamos a perspectiva teórico-metodológica que norteia esse trabalho: buscamos analisar os discursos sociais, conforme define Angenot (2010). Segundo o autor, o discurso social corresponde ao que é pensável e dizível em certo momento histórico, o que faz da atividade de produção discursiva algo estritamente relacionado com o espírito do tempo.

Compreender a relação entre espírito do tempo e o discurso social passa pela noção de hegemonia discursiva: “no 'mercado discursivo' de uma dada época, há sem dúvida objetos temáticos e formações discursivas infinitamente diversas em seu status social, seu regime cognitivo e seus destinatários" (ANGENOT, 2015, p. 53). No entanto, como destaca Angenot, apesar da aparente cacofonia, emerge a cada momento histórico os chamados "lugarescomuns" - “[...] padrões dominantes, homogêneos ou, ao menos, regulados, princípios de coesão, restrições, coalescências que fazem com que o discurso 
social não corresponda a uma justaposição de formações discursivas autônomas [...]", mas sim remetam à onipresença de "temas interdiscursivos", “'maneiras de ver' e de dizer" (ibidem, p. 52) que atribuam uma ideia de organicidade ao Zeitgeist. Em síntese, "a função do discurso social, função concomitante com seu monopólio de representação, é produzir e fixar legitimidades, validades, publicidades (de tornar públicos os gostos, opiniões, informações, valores...)" (ibidem, p. 55).

Nossa abordagem se guia pela instrução geral de Angenot (2015, p. 124): "a análise argumentativa é, de início, inseparável do dialogismo interdiscursivo, da imersão dos textos no discurso social da época e da análise hermenêutica, isto é, aquela da constituição do texto como estratificação dos níveis do sentido". A organização temática do quadro teórico identifica os pressupostos que constituem o contexto da empiria, relativo à configuração dos discursos e suas especificidades. Em síntese, a proposta de Angenot conjuga as particularidades das formações discursivas, os encadeamentos discursivos e a remissão ao dialogismo interdiscursivo, que estabelece a conexão entre os textos, as macroproposições e, em consequência, o espírito do tempo.

De acordo com Boltanski e Chiapello (2009), Ehrenberg (2010), entre outros, o espírito do capitalismo contemporâneo se associa à emergência da figura do empreendedor como modelo de cultura de nosso tempo. Projetado como um ser resiliente, flexível, visionário, heróico, entre outros atributos, o empreendedor é um ser que ultrapassa a atividade de negócios; o maior empreendimento, na perspectiva da sociedade neoliberal (DARDOT; LAVAL, 2016), é empreender a própria vida, gerir o próprio capital humano (FOUCAULT, 2008).

Mas, afinal, por que discutir sobre a cultura empreendedora, se estamos tratando do futuro do trabalho? Do trabalhador se exige atualmente um conjunto de características, de comportamentos e habilidades que correspondem à imagem idealizada do empreendedor. Um desses pontos de conexão dos dois agentes, em outras épocas mais distintos em relação ao outro, é o contexto da precarização do trabalho. Diante de um cenário de demissões em massa e ausência de empregos formais, há uma espécie de contrapartida, um discurso positivo que redireciona a demanda por vagas para a possibilidade de ser "chefe de si mesmo", de se tornar um microempreendedor, de ser "autônomo" - e simultaneamente prestar serviços de forma mediada, por corporações globais do capitalismo de plataforma, como o Airbnb (aplicativo de hospedagens), a Uber (plataforma que mobiliza 
motoristas e entregadores pelas tecnologias móveis, sem constituir vínculo empregatício) e suas concorrentes.

De acordo com Tom Slee (2017, p. 21), “o Vale do Silício abriga uma parcela das pessoas mais ricas do mundo, mas sempre se viu e se apresentou como sendo algo mais do que dinheiro: lá também se construiria um futuro melhor". Essa perspectiva de um futuro promissor vem a reboque dos discursos sobre a Nova Economia, baseada nas tecnologias informáticas e digitais, que alimentaram o imaginário de uma Nova Era, capitaneada por um ambiente de negócios pleno de possibilidades para novos empreendedores. Dessa forma, “a Economia do Compartilhamento [sharing economy] promete ajudar prioritariamente indivíduos vulneráveis a tomar controle de suas vidas tornando-os empresários" (SLEE, 2017, p. 22). No entanto, como bem aponta Slee, "[...] a Economia do Compartilhamento está propagando um livre mercado inóspito e desregulado em áreas de nossas vidas que antes estavam protegidas" (p. 23). Antunes (2018, p. 71) entende esse processo como constituinte de uma nova morfologia do trabalho, baseada numa configuração recente da informalidade: “[...] a informalização da força de trabalho vem se constituindo como um dos mecanismos centrais utilizados pela engenharia do capital para ampliar a intensificação dos ritmos e movimentos do trabalho e ampliar o seu processo de valorização".

Tanto Slee quanto Antunes identificam os processos sociais em curso e os cenários que indicam um futuro distópico, um acirramento das condições precárias do trabalho, em contraponto a um mundo cada vez mais tecnológico. Nesse aspecto, os relatórios sobre o futuro do trabalho que compõem nosso estudo são parte de um cenário comunicacional complexo e difícil de delimitar, de publicização de um novo mundo a partir da economia. É isso que aponta esses documentos como fenômenos comunicacionais: eles "anunciam" um mundo que está por vir, caracterizando uma espécie de utopia pragmática, que dissimula a ideologia na qual se baseia essa edição de mundo, o enquadramento do futuro como discurso.

A partir desses aspectos levantados, definimos o problema da pesquisa: quais são os aspectos ideológicos e elementos discursivos que caracterizam a construção do "futuro do trabalho", presente em relatórios e white papers de instituições que abordam o tema?

Johansen e De Cock (2018), em sua análise das ideologias do tempo, baseiam -se nas teses de Jameson ao adotarem a perspectiva de colonização do futuro pela ideologia do capitalismo. De acordo com os autores: 
O futuro neutralizado do capitalismo contemporâneo perdeu seu potencial de ser um espaço no qual sociedades e organizações alternativas podem se realizar, ou de trazer uma visão utópica que nos faça refletir sobre as disfuncionalidades do presente; baseia-se em convenções de agência racional (JOAS, 1996) que circunscrevem drasticamente nossas habilidades de descrição e imagina-ção (JOHANSEN; DE COCK, 2018, p. 188, tradução nossa)

O exercício de imaginar o futuro, nesse contexto, é restrito a uma derivação das lógicas do sistema capitalista que se afirma como único possível, condição acirrada com a Queda do Muro de Berlim e o fim da Guerra Fria. Uma outra realidade possível, uma outra economia, um outro imaginário deslocado dos preceitos da sociedade neoliberal, são visões restringidas pela racionalidade que naturaliza a condição presente e busca neutralizar, esvaziar as suas dissidências, desde o ato de imaginar e de projetar outras realidades.

Zhan Li (2014), baseado nas teses de Bruner acerca da construção narrativa da realidade, compreende os cenários futuros como narrativas elaboradas para refletir configurações de poder e, simultaneamente, persuadir públicos e legitimar os interesses particulares, dando-lhes credibilidade. A abordagem da realidade como construção narrativa, bem como a lógica concorrencial implícita na presença de múltiplas visões de futuro, são elementos considerados no tratamento do objeto deste estudo. Em termos analíticos, nosso enfoque está na observação e análise crítica dos movimentos retóricos, das lógicas argumentativas, enfim, da constituição discursiva de diversos agentes, que buscam atribuir sentido aos cenários construídos como futuros possíveis.

\section{O futuro do trabalho: análise crítica dos discursos dos white papers}

Entre as noções que guiam a operacionalização da análise do discurso social para este estudo está o conceito de "arsenal argumentativo" (ANGENOT, 2015, p. 100-101), correspondente à análise retórica que ultrapassa a diversidade dos modos de dizer, privilegiando assim o "arsenal breve de meios argumentativos recorrentes" (p. 100, destaques do autor). Angenot se baseia no dialogismo bakhtiniano, filosofia da linguagem que entende os enunciados em diálogo com os discursos que o antecederam, com seus contemporâneos e na projeção de interações futuras. Dessa forma, os argumentos dos relatórios sobre o futuro se relacionam com a hegemonia discursiva, 
com os "lugares-comuns" de sua época, na recorrência e naturalização dos discursos sociais.

Nesse sentido, as análises buscam identificar as recorrências que constroem "idealtipos sustentados por tendências retóricas" (idem). O conceito de idealtipo se aproxima dos núcleos temáticos, ou macroproposições, no sentido de Van Dijk (SERNA, 2004); ou, ainda nos termos de Angenot (2015, p. 101), busca-se observar os "repertórios tópicos e a pressão da hegemonia discursiva". Esses idealtipos têm relação com o contexto histórico; a ideologia do capitalismo neoliberal dá sustentação às formações discursivas presentes em nosso objeto. Em síntese, observamos, na análise empírica, a escolha dos léxicos e sua remissão a formações discursivas, que caracterizam sua especificidade; e a maneira como os encadeamentos argumentativos remetem a padrões que se associam ao espírito do tempo.

Iniciamos nossa análise com uma instituição paradigmática do capitalismo, que representa o espaço onde seu futuro é discutido por líderes do mundo todo: o World Economic Forum (WEF). Tomamos como objeto o relatório The Future of Jobs Report, em sua edição de 2018. Em relação ao contexto dessa produção discursiva, como o próprio nome sugere, o WEF observa o futuro à luz da economia mundial, de suas tendências e projeções. O relatório é o documento final que sugere uma síntese unificadora, o resultado de um debate amplo com as lideranças globais que povoam o encontro de Davos a cada ano. Carrico (2013) aponta como esse exercício de futuro tem um caráter ideológico, ao concluir que

A futurologia dominante ("mainstream") que emerge dos relatórios do Banco Mundial e dos "think-tank white papers" ${ }^{\prime 2}$ em apresentações de diretorias corporativas ou nos TED talks, procura identificar tendências de desenvolvimento e fornecer orientações esboçando cenários especulativos. Mas apesar de sua atual onipresença, há boas razões para questionar a tendência como um objeto analítico legítimo ou um recurso metodológico aplicável (CARRICO, 2013, p. 52-53; tradução livre, destaques nossos).

O relatório The Future ofJobs, segundo a apresentação da instituição, tem sua primeira edição em 2016. O impulso recente para mapear o futuro do trabalho

2 Documentos e relatórios com caráter oficial, publicados por órgãos governamentais ou organizações globais, produzidos em "círculos de reflexão", ou "laboratórios de ideias" - traduções aproximadas do que são os "think-tanks". 
seria derivado da emergência de uma nova era do capital, como expresso no prefácio do executivo chefe e fundador do WEF, Klaus Schwab: “Os contornos emergentes do novo mundo do trabalho na Quarta Revolução Industrial estão rapidamente se tornando uma realidade vivida para milhões de trabaIhadores e empresas em todo o mundo" (WEF, 2018, p. V, tradução nossa).

Parece não haver grandes polêmicas em se constatar que o sistema capitalista, em tempos recentes, passa por grandes transformações. Sob a égide do capitalismo flexível (SENNETT, 2007), vimos surgir novas noções que identificam fenômenos e circunstâncias relativos ao acirramento dos processos de exploração da mão de obra, em compasso com o desmonte das leis e garantias trabalhistas, das conquistas históricas das classes que vivem do trabalho. No entanto, o relatório da WEF sinaliza para uma abordagem evolucionista no cerne do próprio capital, uma nova "revolução":

As oportunidades inerentes à prosperidade econômica, ao progresso da sociedade e ao florescimento individual neste novo mundo do trabalho são enormes, mas dependem crucialmente da capacidade de todas as partes interessadas em estimular reformas nos sistemas de educação e treinamento, políticas do mercado de trabalho, abordagens comerciais para o desenvolvimento de habilidades, acordos de emprego e contratos sociais existentes. Catalisar resultados positivos e um futuro de bom trabalho para todos exigirá liderança ousada e um espírito empreendedor de empresas e governos, além de uma mentalidade ágil de aprendizado ao longo da vida dos funcionários (WEF, 2018, p. V, tradução nossa).

Destacamos, no trecho acima, a retomada de um arsenal argumentativo tradicional: o discurso de prosperidade e progresso associados historicamente aos discursos do capitalismo, desde a sua emergência no século XIX. Ao mesmo tempo, coloca-se o condicionante de ações a serem tomadas para aproveitar as "oportunidades" de mudança - que se referem a reformas, e não a revoluções no cerne do sistema. O "espírito empreendedor" dos governantes privados e públicos, assim como a "mentalidade" flexível para o aprendizado de novas aptidões caracterizam uma relação de parceria entre desiguais, unidos pela imagem do empreendedor como paradigma para um futuro positivo. O idealtipo do empreendedorismo se faz presente e identificável por esses elementos lexicais que remetem à formação discursiva do capitalismo neoliberal. De forma evidente, a imagem do empreendedor, em "espírito" e "mentalidade", corresponde à sua disseminação como código 
hegemônico, ainda mais quando se torna protagonista no diagnóstico de um relatório sobre "empregos" ("jobs"), e não sobre economia criativa, inovação, startups - o cenário de novos negócios e projetos onde esses agentes geralmente se situam.

Por ser tributário de uma leitura revolucionária do capital, da "Quarta Revolução Industrial" que estaria em curso, o relatório aponta, entre as suas principais conclusões ("key findings") os "motores da mudança" ("drivers of change") baseados nas tecnologias digitais, a adoção acelerada das inovações tecnológicas. Nessa perspectiva, destaca a tendência da "robotização":

[...] uma gama mais ampla de tecnologias robóticas recentes na ou perto da comercialização - incluindo robôs estacionários, não humanóides robôs terrestres e drones aéreos totalmente automatizados, além de algoritmos de aprendizado de máquina e inteligência artificial - estão atraindo interesse comercial significativo para sua adoção. As taxas de adoção de robôs divergem significativamente entre os setores, com $37 \%$ a $23 \%$ das empresas planejando esse investimento, dependendo do setor (WEF, 2018, p. VII, tradução nossa).

A robotização da produção capitalista é um tema recorrente em relatórios sobre o futuro do trabalho; a figurativização do discurso baseada na imagem do robô estabelece uma relação interdiscursiva com o imaginário mobilizado pela ficção científica. Esse diagnóstico, como o próprio white paper da WEF sugere, não se associa a um futuro construído de forma coletiva, mas sim às decisões econômicas em curso dirigidas pelos grandes players do mercado capitalista. A retórica do mercado, como hegemonia discursiva, atravessa e encadeia a argumentação sobre o futuro possível, deslocando o imaginário ficcional para a visão "concreta" dos números e das possibilidades comerciais. O relatório deixa entrever o cenário de uma inevitável (e positiva) convivência com os robôs, no dialogismo com possíveis críticas e leituras negativas futuras; uma visão utópica, eufórica em torno de tarefas emergentes e do crescimento do emprego, que poderiam compensar os dados reveladores sobre o declínio de postos de trabalho:

Um conjunto de estimativas indica que 75 milhões de empregos podem ser substituídos por uma mudança na divisão do trabalho entre humanos e máquinas, enquanto 133 milhões de novos papéis podem surgir mais adaptados à nova divisão do trabalho entre humanos, máquinas e algoritmos (WEF, 2018, p. VIII, tradução nossa). 
Destacamos a retórica que anuncia um futuro de via única, baseado na monocultura tecnológica do capital - uma macroproposição cuja historicidade remete às origens das tecnologias que impulsionaram a emergência e a consolidação do capitalismo como sistema hegemônico. Dessa forma, "humanos, máquinas e algoritmos" passam a compor o futuro do trabalho, numa leitura da divisão social do trabalho que dissimula as questões de poder, das desigualdades sociais, disputas e desequilíbrios econômicos inerentes ao capitalismo globalizado. Aplicado ao cotidiano da atividade laboral, o cenário construído sugere a inevitabilidade desse futuro construído pelo relatório, assim como afirma uma visão harmônica da relação entre o ser humano e os elementos tecnológicos que progressivamente povoam o mundo do trabalho.

O diagnóstico do relatório do WEF indica as ações empresariais a serem tomadas - tornando explícito o caráter prescritivo da projeção futura que posiciona como protagonistas os líderes empresariais globais:

As novas tecnologias podem impulsionar o crescimento dos negócios, a criação de empregos e a demanda por habilidades especializadas, mas também podem substituir funções inteiras quando determinadas tarefas se tornam obsoletas ou automatizadas. As lacunas de habilidades tanto entre os trabalhadores quanto entre a liderança das organizações - podem acelerar as tendências em direção à automação em alguns casos, mas também podem representar obstáculos à adoção de novas tecnologias e, portanto, impedir o crescimento dos negócios (WEF, 2018, p. IX, tradução e destaques nossos).

Em relação às "lacunas de habilidades", o relatório aponta, mais adiante, para um conjunto de "novos papéis" ("new roles") a serem desenvolvidos para ocupar o espaço do trabalho do futuro, nesse capitalismo desenhado pelos dados mobilizados pela instituição. A recorrência do "arsenal argumentativo" é evidente: todas as funções da extensa lista se referem a habilidades e competências em torno de gerenciamento e desenvolvimento de tecnologias digitais, de inteligência artificial, de controle de informação, de robótica, de inovação (WEF, 2018, p. 9). Assim como as tendências das habilidades para o não tão distante ano de 2022 (2018, p. 12) elencam características e comportamentos identificados com a cultura empreendedora na contemporaneidade: "inteligência emocional"; "Criatividade, originalidade e iniciativa"; "Liderança e influência social" - entre outros elementos lexicais advindos da formação discursiva do empreendedorismo, associados à produção do sujeito neoliberal para o futuro desenhado pelo World Economic Forum. 
O outro relatório analisado se enquadra no cenário construído pelo WEF e expande alguns de seus significados - trata-se do material da Dell (empresa global de tecnologia), que proclama a "próxima era de parcerias homem-máquina" (DELL, 2019). Desenvolvido em parceria com o Institute for the Future, uma organização não-governamental sediada em Palo Alto, Califórnia (berço da cultura do Vale do Silício, o epicentro do novo espírito do capitalismo), o breve relatório (de 18 páginas, com diversas ilustrações) desenha um futuro mais longínquo do que o WEF: o ano de 2030. O contexto que estimula essa produção discursiva é sugerido pela breve apresentação do estudo à imprensa ${ }^{3}$, quando trata das duas instituições envolvidas.

No caso do Institute for the Future, o estudo é justificado nesses termos: "Nossa pesquisa gera a previsão necessária para criar insights que levam a ações e abrange um vasto território de futuros profundamente transformadores, da saúde à tecnologia, mercado de trabalho, aprendizagem e identidade humana". Ou seja, o instituto revela, nesse trecho, fazer parte de um mercado de tendências, referindo-se à sua formação discursiva ("criar insights") voltada a subsidiar a "tomada de decisões" mercadológicas. Essa leitura é corroborada pela apresentação da Dell Technologies, "[...] uma família única de negócios que fornece a infraestrutura essencial para as organizações construírem o futuro digital, transformarem a Tl e protegerem o ativo mais importante: a informação". A empresa se localiza como fornecedora da base tecnológica de um mundo futuro que ela mesma anuncia; o léxico "família" sugere uma forma de humanizar o conglomerado global de corporações que a marca representa. A retórica permite entrever a intencionalidade do discurso em produzir um cenário prospectivo protagonizado pela Dell, que trabalha para produzir as "tecnologias emergentes que 'rearquitetam' o mundo do trabalho":

Quatro tecnologias emergentes são extremamente importantes para entender como humanos e máquinas podem trabalhar em harmonia para aproximar as pessoas de um trabalho significativo, criativo e sustentável, além de melhorar a colaboração dentro e entre as organizações. Essas tecnologias são: IA colaborativa, interfaces multimodais, realidade estendida (XR) e registros distribuídos seguros (DELL, 2019, p. 2, tradução nossa). 
Temos, no trecho acima, o enquadramento das tecnologias "emergentes"como redesenho definitivo do mundo do trabalho - que, na retórica do documento prospectivo, não significa uma ênfase no princípio tecnológico para sobredeterminar a atividade humana, o que poderia gerar reações negativas ou desconfianças por parte de seus leitores mais preocupados com os cargos que podem ser extintos nesse processo. Pelo contrário, o dialogismo se faz perceber pela atitude responsiva do relatório: esse protagonismo dado às tecnologias serviria à conciliação do humano com o seu "propósito" de trabalho, com o estímulo à sua criatividade e com a "sustentabilidade", numa aplicação vaga dessa noção às práticas laborais. Nesse aspecto, identificamos uma relação interdiscursiva entre o futurismo tecnológico da Dell e os discursos da autoajuda; a psicologia positiva é caracterizadora desses discursos, e também é verificável no mundo projetado pela corporação.

Marín-Diaz (2015) relaciona as características fundamentais dos discursos de autoajuda: a interpelação dos sujeitos para a autotransformação; a forma prescritiva de indicar os modelos de sucesso e felicidade valorizados por essa cultura, que devem resultar da mudança. O discurso assumido pela Dell é grandiloquente, e parece não estabelecer limites para o alcance do uso das tecnologias, em sua visão positiva:

\footnotetext{
As parcerias homem-máquina que emergem na próxima década podem ajudar a realizar as metas e objetivos delineados pelas Nações Unidas e ecoar nas políticas nacionais em todo o mundo. Elas oferecem as possibilidades de criar maneiras mais equitativas de preparar e conectar pessoas, principalmente jovens e mulheres, a oportunidades de geração de renda. E as parcerias homem-máquina permitem novas abordagens para partilhar a tomada de decisão e a colaboração entre redes de trabalhadores (DELL, 2019, p. 5, tradução nossa).
}

No discurso da Dell, percebemos as estratégias de positivação de um cenário que pode acirrar o fosso das desigualdades sociais a partir do mundo do trabalho. De acordo com Jacques Barcia, "futurista e narrative hacker" e "membro da Association of Professional Futurists (APF)": "O futuro é uma bataIha constante entre narrativas. Algumas dessas narrativas não desejam o melhor para todos" (MENA, 2017). Em termos retóricos, essas intencionalidades não são explicitadas, e a noção de "propósito" é um recurso para a legitimação das instituições e suas ações. 
O texto traz um curioso percurso retórico, que procura ultrapassar o caráter mercadológico e competitivo do mercado - identificável pela apresentação das entidades responsáveis pelo relatório - por meio da escolha de uma formação discursiva que aproxima essas instituições e suas intencionalidades de um universo associado ao bem comum. Para isso, utiliza elementos textuais sobre "equidade" e mesmo a referência direta à criação de "oportunidades de geração de renda", fazendo menção às políticas e consensos da ONU em torno de direitos humanos, de combate às desigualdades. Esses recursos servem como arsenal argumentativo que justifica as operações do sistema capitalista, na postura responsiva aos seus possíveis críticos (BOLTANSKI; CHIAPELLO, 2009). Aqui se identifica uma marca dialógica, uma atitude de antecipação retórica inscrita na argumentação, como antídoto aos possíveis ataques contra as ações corporativas e suas intenções de lucro em um mercado globalizado, em que a Dell atua com destaque.

\section{Considerações finais}

Em nossa análise do discurso social sobre o futuro do trabalho, constatamos a presença norteadora da ideologia da sociedade neoliberal: ou seja, a reiteração das convocações à gestão do capital humano e da naturalização dos processos de "economização" da vida, sob a ótica do mercado. Também observamos o idealtipo relacionado ao discurso revolucionário que projeta o homem no futuro sobredeterminado pela organização maquínica da existência - numa recorrência do arsenal argumentativo associado às tecnologias digitais, em chave positiva. No entanto, o olhar para a constituição das formações discursivas ultrapassa a mera constatação do futuro projetado sob a égide do capitalismo neoliberal, por mais que essa seja a ideologia que organiza as metaproposições dos relatórios. O discurso humanista da ONU, a remissão (mesmo que involuntária) aos gêneros da ficção científica e da autoajuda nuançam as também (oni)presentes associações à hegemonia discursiva do mercado.

Os discursos dos relatórios do WEF e da Dell evidenciam o mundo construído que dissimula as mazelas do capitalismo e os riscos evidentes de uma adoção radical das tecnologias para o trabalho do futuro, em estratégias retóricas com nuances distintas.

O relatório da Dell afirma a presença decisiva da tecnologia computacional, sua mercadoria principal, no enquadramento do futuro construído 
narrativamente; sua visão eufórica é superlativa, a ponto de ressignificar o processo de automatização do trabalho em termos humanistas. Nesse sentido, apropria-se de discursos como as metas da ONU para afirmar um capitalismo salvacionista, que teria como objetivo central a progressão positiva da condição humana. O que o relatório não revela é como o capitalismo contemporâneo - orientado para a competitividade extrema no mercado globalizado, para o lucro acima de qualquer direito trabalhista, para a negligência com as responsabilidades e leis que deveriam reger o mercado pode se transformar radicalmente em tão pouco tempo, até 2030, o cenário imaginado pelo documento. O cenário utópico revela, na verdade, os caminhos para a renovação retórica do sistema, no sentido da teoria do novo espírito do capitalismo (BOLTANSKI; CHIAPELLO, 2009). Renovando-se para continuar o mesmo, adequando-se ao espírito de seu tempo e respondendo a seus críticos, ao incorporar a crítica na sua reproposição discursiva.

No caso do white paper do WEF, o discurso oscila entre a visão da automatização do trabalho futuro, com diagnósticos direcionados a uma leitura revolucionária do capitalismo e da emergência de novas competências dos trabalhadores; e as prescrições dirigidas aos players do mercado — os capitalistas que, com seu poder econômico, podem transformar o futuro tendo como norte as oportunidades de negócios e seus interesses particulares. Explicita-se a convocação para que esses agentes do capital invistam na formação de mentalidades e competências dos trabalhadores compatíveis com esse projeto futuro de sociedade neoliberal extremamente automatizada. A fábrica do sujeito neoliberal (DARDOT; LAVAL, 2016), ganha ares de ficção científica distópica, mas revestida pela visão positiva do WEF. Dessa forma, a imagem do empreendedor, amplamente difundida na atualidade, é reposicionada como meta futura para a produção de novos sujeitos, para um novo mundo desenhado pela eficácia da produção capitalista, que reserva ao homem um lugar único de parceria e harmonização obrigatória com a figura do robô.

Nesse ponto, é quase inevitável a remissão à obra ficcional que criou o termo robô, a distopia escrita por um dos mais importantes autores tchecos do século XX, Karel Tchápek. Como aponta Jovanović (2010), no prefácio da edição recente de $A$ fábrica de robôs, a peça teatral de 1920: 


\begin{abstract}
as "qualidades desnecessárias" que marcam os seres humanos, ou seja, não possuem criatividade alguma, não sentem dor nem possuem qualquer espécie de sentimentos. Nessa sociedade, imaginada por Tchápek, os robôs acabam assumindo todos e quaisquer encargos humanos, de modo a racionalizar por completo o processo de produção. Enquanto se atingem níveis máximos de produtividade, a vida humana torna-se banal, monótona, quase sem horizontes, e os homens submergem no gigantesco complexo técnico-industrial como ingrediente praticamente sem importância (JOVANOVIĆ, 2010, p. 18).
\end{abstract}

Na esteira de Tchápek, questionamos o cenário futuro dos relatórios analisados em que o homem deve se adequar ao robô, incorporando traços quase inumanos organizados sob a imagem mítica do "empreendedor". A ficção do passado parece esboçar um futuro tão profético quanto tenebroso. Em síntese, verificamos, por meio das análises, a presença de um discurso eufórico, o anúncio de um novo e maravilhoso mundo, de harmonia entre homens, máquinas e algoritmos. A perversidade dessa retórica nos demanda o exercício da crítica - como ato efetivamente humanista, que objetiva desnaturalizar e descolonizar o futuro construído a partir dos preceitos e interesses dos líderes globais do capitalismo de nosso tempo.

\begin{abstract}
Vander Casaqui é professor titular do Programa de Pósgraduação em Comunicação Social da UMESP. É bolsista CNPq e doutor em comunicação pela USP, com pós-doutorado pela Universidade Nova de Lisboa.
\end{abstract}

vander.casaqui@gmail.com

\title{
Referências
}

AGAMBEN, G. O que é o contemporâneo? e outros ensaios. Chapecó (SC): Argos, 2009.

ANTUNES, R. O privilégio da servidão: o novo proletariado de serviços na era digital. São Paulo: Boitempo, 2018.

ANGENOT, M. El discurso social: los limites históricos de lo pensable y lo decible. Buenos Aires: Siglo XXI, 2010.

O discurso social e as retóricas da incompreensão: consensos e conflitos na arte de (não) persuadir. São Carlos: EduFSCar, 2015.

BOLTANSKI, L.; CHIAPELLO, È. O novo espírito do capitalismo. São Paulo: Martins Fontes, 2009. 
CARRICO, D. Futurological discourses and posthuman terrains. Existenz, vol. 8, no. 2, 2013, p. 47-63.

DARDOT, P; LAVAL, C. A nova razão do mundo: ensaio sobre a sociedade neoliberal. São Paulo: Boitempo, 2016.

DELL. Future of work: forecasting emerging technologies' impact on work in the next era of human-machine partnerships. Palo Alto (EUA): Institute for the Future / Dell Technologies, 2019.

EHRENBERG, A. O culto da performance: da aventura empreendedora à depressão nervosa. Aparecida - SP: Ideias \& Letras, 2010.

FOUCAULT, M. Birth of biopolitics. New York: Palgrave Macmillan, 2008.

JOHANSEN, C. B.; DE COCK, C. Ideologies of time: how elite corporate actors engage the future. Organization, vol. 25, n. 2, 2018, p. 186-204.

JOVANOVIĆ, A. Introdução. In: TCHÁPEK, K. A fábrica de robôs. São Paulo: Hedra, 2010, p. 9-23.

LI, Z. T. Narrative rhetorics in scenario work: sensemaking and translation. Journal of Futures Studies, March 2014, 18(3), 2014, p. 77-94.

MARÍN-DÍAZ, D.L. Autoajuda, educação e práticas de si: genealogia de uma antropotécnica. Belo Horizonte: Autêntica, 2015.

MENA, I. Verbete Draft: o que é futurismo. Projeto Draft, 9 ago. 2017. Disponível em: <https://projetodraft.com/verbete-draft-o-que-e-futurismo/>. Acesso em: 18 jul. 2019.

MORACE, F. O que é o futuro? São Paulo: Estação das Letras e Cores Editora, 2013.

SCHWARTZ, Y. Conceituando o trabalho, o visível e o invisível. Trab. Educ. Saúde, Rio de Janeiro, v. 9, supl.1, 2011, p. 19-45.

SERNA, O. M. Análisis del discurso social. Investigaciones Sociales, año VIII, n 13, 2004, p. 369-385. Lima: UNMSM / IIHS.

SENNETT, R. A corrosão do caráter: consequências pessoais do trabalho no novo capitalismo. Rio de Janeiro: Record, 2007.

SLEE, T. Uberização: a nova onda do trabalho precarizado. São Paulo: Ed. Elefante, 2017. WEF. The Future of Jobs Report 2018. Cologny/Geneva: World Economic Forum, 2018. 